Review

\title{
Electroosmotic Stabilization on Soft Soil: Experimental Studies and Analytical Models (A historical review)
}

\author{
Yimin Liu ${ }^{1,2}$, Xinyu Xie ${ }^{1,2, *}$, Lingwei Zheng ${ }^{2}$, Jinzhu Li $^{2}$ \\ ${ }^{1}$ Research Center of Coastal and Urban Geotechnical Engineering, Zhejiang University, Hangzhou \\ 310058, China. \\ ${ }^{2}$ Ningbo Institute of Technology, Zhejiang University, Ningbo 315100, China. \\ *E-mail: xiexinyu@zju.edu.cn
}

doi: $10.20964 / 2018.09 .40$

Received: 9 May 2018 / Accepted: 20 June 2018 / Published: 5 August 2018

\begin{abstract}
Electrokinetic stabilization is a newly developed technique, which was pioneered by Cassagrand in 1940 and has been employed in railway embankment stabilization. Compared with conventional foundation treatment methods, electrokinetic stabilization performs more effectively with shorter times on soft clay foundations with a high content of fine grains and a low hydraulic coefficient. However, electroosmosis (EO) has not been widely used in practical engineering, especially in large-scale applications, due to a lack of understanding of the mechanism of EO treatment and the errors between the theoretical predictions and experimental results, which cannot be ignored. The purpose of this paper is to briefly review the history of electrokinetic stabilization on soft soils, including investigations into the mechanism, laboratory and field tests of the critical influencing factors, and the development of theoretical and numerical models and methods to improve the efficiency of EO treatment. In addition, directions for future research are discussed.
\end{abstract}

Keywords: Electrokinetic stabilization; Foundation treatment; Mechanism of EO treatment; Electrokinetic geosynthetics (EKG); Analytical and numerical solutions.

\section{$\underline{\text { FULL TEXT }}$}

(C) 2018 The Authors. Published by ESG (www.electrochemsci.org). This article is an open access article distributed under the terms and conditions of the Creative Commons Attribution license (http://creativecommons.org/licenses/by/4.0/). 